\title{
BRIDGING THE GAP BETWEEN CULTURE AND SAFETY IN A CRITICAL CARE CONTEXT: THE ROLE OF WORK DEBATE SPACES
}

\author{
Geoffrey LEURIDAN \\ IMT Atlantique, LEMNA (France) \\ geoffrey.leuridan@imt-altantique.fr
}

\section{Highlights}

- This study investigates how structural spaces connect safety, medical practices and organizational culture.

- The empirical field takes place in a critical care unit using an ethnographic approach.

- Structural spaces take the form of "work debate spaces".

- Work debate spaces play a key role in building safe medical practices through formal and informal spaces.

- Work debate spaces offer a finer-grained approach to the relationship between culture, safety and activity over time.

\begin{abstract}
From the beginning, studies on reliability and safety have highlighted the crucial role of organizational culture. However, culture, context and groups of individuals are highly intertwined, making the culture difficult to manipulate and steer. Like Hopkins (2019), this study considers that taking only a "hearts and minds" approach to safety is ineffective without appropriate organizational structures. An interesting research avenue is therefore to understand the relationship between organizational structure and culture over time. This research took the form of an ethnographic study carried out in a French critical care unit to examine how structural spaces - in the form of "work debate spaces" - can connect safe medical practices and organizational culture. The study shed light on two types of work debate spaces: formal and informal spaces. These inter-related work debate spaces enable a more refined approach to understanding the relationship between structure and culture.
\end{abstract}

\section{Keywords}

Work debate space; Activity; Culture; Ethnographic approach; Critical care unit 


\section{BRIDGING THE GAP BETWEEN CULTURE AND SAFETY IN A CRITICAL CARE CONTEXT: THE ROLE OF WORK DEBATE SPACES}

\section{Introduction}

Organizational culture enables knowledge, beliefs, attitudes and artifacts to be shared between the members of an organization (La Porte, 1996; Schein, 1990; Weick \& Roberts, 1993) and is an evolving phenomenon (Denison, 1996). For organizations working in extreme contexts (Hällgren et al., 2018), a culture of safety - i.e. an organizational culture where safety is the first priority (Reason, 1997) - becomes the main concern, directly linking the issues of "having a culture of safety" with "performing in a safe manner". However, culture, context and groups of individuals are highly intertwined, making culture difficult to manipulate and steer (Gilbert et al., 2018). Literature on reliability and resilience emphasizes the importance of culture (Roberts et al., 1994; Weick, 1987) in relation to processes involved in the situation. Being reliable or resilient in a situation is therefore the consequence of long-term elements beyond the situation encountered. These complex relationships raise questions about how daily work and organizational culture are connected. Studies on work debate spaces (WDS) (e.g. Detchessahar, 2013; Rocha et al., 2015, 2019) highlight the importance of organizations providing space for the reconstruction of situations encountered in order to ensure reliability and resilience. This reconstruction work involves cultural, structural and situational elements in a dynamic and interdependent relationship. However, few studies have so far explored the concrete functioning of WDS (Rocha et al., 2019). To understand how structural spaces can connect safe medical practices and organizational culture, this paper investigates WDS in a critical care context.

The article first examines how organizational culture relates to the literature on organizational reliability and safety, and how WDS can connect the situational and organizational levels. The second section presents the empirical field and the ethnographic methodology used. Based on the data analysis, the results section highlights the role of WDS and their organizational implications as structures that carry collective experience over time. The final section discusses the contributions this study makes to the concept of WDS, to the literature on reliability and resilience, and to the relationships between organizational structure and culture.

\section{Theoretical Framework}

\subsection{The crucial role of culture to improve organizational reliability}

Hopkins (2019, p. 29) defines culture as "the way we do things around here", emphasizing the normative (the way), collective (we do) and embedded (around here) dimensions. There is therefore a strong connection between culture, context and individuals, which makes its manipulation and orientation difficult, especially in the short term. From the beginning, 
studies into high-reliability organizations (HROs) have highlighted the role of organizational culture (e.g. Roberts, 1990; Weick, 1987; Weick \& Roberts, 1993). Those that focus on culture in HROs highlight "strong" culture - found in the military in particular - which is marked by values, rituals, codes and uniforms, etc. For example, through stories and anecdotes, culture conveys the potential mistakes that should be avoided (Weick, 1987). This vector is even more effective due to the form of the message. Stories (narratives, anecdotes, myths, etc.) play an important role in facilitating the communication of expected values or behaviors. For new group members, there is a process of acculturation through which the newcomer becomes a legitimate member of the group (Bierly \& Spender, 1995). It should also be noted that the values conveyed by culture impact how members of the organization perceive a problem and how they will act accordingly (Weick \& Sutcliffe, 2007).

Culture is a foundation for creating knowledge and meaning, and it is therefore a key element of management of the unexpected. It is through its organizational culture that the paradox of a system that is both centralized and decentralized can be solved (Roberts et al., 1994). The organizational culture centralizes to socialize so that actors have the same value system, thereby ensuring coordination of decentralized operations. Unlike regulation through standardization and hierarchy, culture makes it possible to ensure behavioral compliance without constant monitoring (Weick, 1987), offering greater responsiveness to extreme situations.

\subsection{The Complex Relationship between Culture and Safety}

As well as reliability and resilience, ensuring the safety of an organization cannot be achieved without a culture which conveys the right values and behaviors that emphasize safety. A "safety culture" can be structured around three key elements: 1) concern for danger and risk, which makes it possible to be aware of the consequences in the event of failure; 2) the safety of the activity as a matter of priority; and 3) the flexibility of responses in unexpected situations in order to maintain a coherent system of action (Pidgeon, 1997). But creating a safety culture is complex and requires a lot of resources and time on the part of the organization and its members (Weick \& Sutcliffe, 2007). Moreover, the causal relationship between culture and safety should not be oversimplified. The diffusion and evolution of culture and its role in safety are more complex than linear causal relationships, and some mechanisms from other processes will undermine the potentially negative effect of culture on the integrity of the organization. For example, a value should not be judged as "wrong" because it is promoted by a culture and is one of the explanatory causes of an accident (Hopkins, 2006). Changing culture is far more complex than applying good principles. As Cole, Stevens-Adams and Wenner (2013) explain, it is one thing to study safe principles in a specific organizational culture, but it is another to use these principles in a normative way: "focusing on individuals through enforcing compliance is not enough to change culture" (Cole et al., 2013, p. 38).

Finally, transforming the organizational culture to improve safety emphasizes the unsettled nature of culture, and raises question about its temporal dimension. While culture is historically rooted in an organization, it is not fixed in the past. It is not a monolith 
representing a crystallized vision of the past; rather, it is an evolutionary process of consensus, dissension and confusion at the same time (Weick \& Sutcliffe, 2007). Culture can be viewed as the dynamic process of socialization of members of a group which perpetuates and evolves the culture (Schein, 1990) supported by structural spaces like WDS.

\subsection{Connecting Organizational Culture and Working Situations through Work Debate Spaces}

According to Hopkins (2019), structure influences culture because safety cannot be achieved only by individual measures. However, others see safety in a more decentralized way, where individuals are the solution to and not the problem for safety issues, and organizations should avoid infantilizing taking autonomy away from workers (Dekker, 2017). Beyond this polarizing debate on the importance of either structure or individuals, it can be interesting to focus on the activity and the working situations encountered. Indeed, the relationship between the situations experienced and long-term organizational elements, such as culture, remains poorly developed in the literature. While Weick (1987) insists on the construction of culture over time, and the importance of building a social structure within the organization to ensure this interaction between situation and organization, he pays little attention to formalizing this articulation, remaining focused on the individuals in the situation. Bechky and Okhuysen (2011) confirm the idea that long-term processes such as the development of culture cannot be ignored in the study of situations to understand how reliability and safety are ensured. In this view, the concept of WDS (Detchessahar, 2013; Detchessahar \& Journé, 2018; Rocha et al., 2015 , 2019) can enable a better understanding of the relationship between situations encountered and long-term aspects.

Recent studies on WDS in both the resilience (Detchessahar et al., 2017) and safety (Rocha et al., 2019) literature consider WDS as a way to connect the formal organization with the living organization "to make the daily experiences visible, so that local arbitrations are the starting point of organizational changes" (Rocha et al., 2015, p. 108). As Grote (2012) points out, discussion about the work experience within an enterprise is the best way to improve safety. Such discussion can take several forms: exchange, feedback, debate, negotiation, etc. A WDS is a vehicle for constructing collective action through the dialogue between interdependent actors: "[...] the discussion about the work, in the plane of the action, in a regular and protected way, coordinated by a manager, being able or not, depending on the subject, to have a hierarchical relationship with team members" (Rocha et al., 2019, p. 193). Organizational spaces are necessary to support discussion in order to produce the outcomes expected from the debate (Detchessahar \& Journé, 2018). The organization should allow this type of space to ensure a collective reconstruction of situations encountered and to ultimately ensure reliability and safety (Rocha et al., 2015). Over time, these organizational spaces bring a more interactive and horizontal perspective to the daily life of the activity: the manager becomes less of a controller and more of a coordinator (Rocha et al., 2019). The WDS concept should therefore be approached both from a communication angle and an organizational angle. Thus, a WDS serves as a vehicle for organizational processes of learning, changing practice and ultimately improving performance (in the multidimensional sense of performance and not just its economic or financial dimensions). 
Organization studies highlight the central role of culture in creating safety. However, the requirement to build a culture of safety can be an impossible challenge, or a way to hide deeper organizational issues or avoid studying what an organization puts in place to improve safety. However, the "hearts and minds" approach of safety alone tends to dwindle over time (Hudson, 2007) and is ineffective without appropriate structural change (Hopkins, 2019). Understanding the relationship between safety, organizational structure and culture through work situations is therefore an interesting avenue for research. This paper investigates how WDS can connect safe medical practices and organizational culture in the context of a critical care unit (CCU), characterized by life-threatening emergencies, unexpected situations and high variance of activity. In order to study the relationships between structural spaces, activity and culture, the fieldwork took the form of a 14-month ethnographic study conducted in a CCU linked to the Emergency Center of a French university hospital. The next section describes this fieldwork and the methodology undertaken.

\section{Fieldwork and Methods}

\subsection{A CCU as empirical field}

A growing body of literature has been extending the study of HROs to new areas of activity, including the healthcare sector (e.g. Bourrier, 2011; Gaba et al., 2003; Madsen et al., 2006; Roberts et al., 2005). Healthcare organizations - hospitals, clinics and operating rooms or medical units - are therefore new areas for research on safety: they are "the newest member of the HRO club" (Bourrier, 2011, p. 12). Studying these organizations opens up new theoretical and managerial contributions because of the issue of safety in such organizations. However, medicine is at an earlier stage of development in relation to the issue of safety, compared to the aviation sector for example, (Amalberti \& Wioland, 1997; Reason, 2005). Even though patient safety ${ }^{1}$ is a main concern - especially after the To Err Is Human report (Kohn et al., 2000) - error in medicine is still a sensitive topic.

Our fieldwork takes place in a CCU linked to the Emergency Center of a French university hospital - one of the biggest in the country. The CCU is only one component of the Emergency Center, which has several other medical units such as the Emergency Department and Pediatric Emergency Department. Within the Emergency Center, the CCU is responsible for patients with critical conditions such as cardiopulmonary arrest, polytraumatic injuries and strokes. There are two essential elements to this type of unit: it is the point of entry for unplanned patients (like any other emergency unit) and it deals with life-threatening events. The unit's staff regularly has to manage unanticipated events in a complex technological and organizational environment with potentially dramatic consequences.

The CCU's operations require access to various technical resources, both inside the unit (monitoring devices, life-support systems, specific technical devices, computers, etc.) and

\footnotetext{
${ }^{1}$ The World Health Organization defines patient safety as "the absence of preventable harm to a patient and reduction of risk of unnecessary harm associated with health care to an acceptable minimum. An acceptable minimum refers to the collective notions of given current knowledge, resources available and the context in which care was delivered weighed against the risk of non-treatment or other treatment".
} 
outside the unit (CT-scanner, MRI scanner, X-Ray, blood bank, etc.). These technical resources enable the $\mathrm{CCU}$ to be considered as a trauma center, i.e. an organization that is able to manage all traumas without having to transfer the patient to a dedicated unit. The other resources required for patient care, whether technical or human, are available within the hospital and can be forwarded to the unit; the resources come to the patients rather than the patients going to the resources.

Whether it is a working day or a holiday, night or day, the unit always has the same number of staff. The staff includes nurses, assistant nurses (orderlies), doctors and interns (who specialize in intensive care anesthesiology). After taking account of leave and sick days, a total staff of 40 works shifts to ensure a continuous service: one doctor, one intern, four nurses and four orderlies are always on shift in the CCU. The interns are different as they work as trainees in the department for a six-month period. They move on at the end of their training period and are then replaced by new interns. The unit takes care of around 3,000 patients per year, with the length of stay generally ranging from a few minutes (especially if the patient is being monitored before surgery) to a maximum of 72 hours (although the problem of finding a bed for some patients can result in stays that sometimes last several weeks). The number of patients admitted each day can be between one and a maximum (observed) of fifteen. Similarly, the variance in the severity of cases (ranging from fractures to very serious polytrauma) and different types of pathology (neurosurgical, visceral, cardiac, etc.) is very high. Moreover, a wide range of circumstances can lead to patients being admitted: car accident, falling off a roof, gunshot wound, parachute jump where the parachute did not open, as well as aneurysms, strokes and post-surgical complications, etc.

\subsection{Ethnographic Approach and Data Collection}

Since the Institute of Medicine's Report To Err Is Human (Kohn et al., 2000), the importance placed on patient safety and its relationship to error highlights a major shift in medicine, which now takes organizational and human factors into account. New avenues are being explored to consider patient safety as the primary objective of these organizations. While a first approach tried to follow good practice from other sectors of activity, a second, more analytically oriented approach considered concepts around safety in order to analyze field activity more closely (Bourrier, 2011). This study takes a more grounded approach to better understand the specificities of medicine and to study the functioning and practices currently in place and their relationship to safety in the medical unit.

The fieldwork took the form of a 14-month ethnographic study inside the CCU, which allowed the researcher to report on the daily life of the organization and to study the actors and/or their social environment over a long period of time. The methodology combined participant observation with semi-structured interviews and secondary data (Table 1) to refine and validate an abductive analysis which consisted in going back and forth between theory and empirical material (Van Maanen et al., 2007). 
Table 1 - Data collection

\begin{tabular}{|c|c|c|}
\hline Participant observation & Interviews & Documentation \\
\hline $\begin{array}{l}\text { October } 2013 \text { - December } \\
2014 \text { (14 months) including: } \\
\text { - Daily observations }(100+) \\
\text { - } 24 \text { h shifts* }(11)\end{array}$ & $\begin{array}{l}\text { Before observation period: } \\
\text { - Exploratory interviews (3) } \\
\text { During observation period: } \\
\text { - Semi-structured interviews } \\
\text { (11) } \\
\text { - Informal interactions } \\
\text { (multiple) }\end{array}$ & $\begin{array}{l}\text { - Internal documentation (98): } \\
\text { guidelines, meeting reports, } \\
\text { activity reports, etc. } \\
\text { - External documentation (222): } \\
\text { national reports, learned society } \\
\text { notices, press articles, etc. }\end{array}$ \\
\hline
\end{tabular}

*In this context, a shift refers to being in the CCU for 24 hours

In addition to collecting data, ethnography consists of "living" with a group and sharing mutual experiences (Van Maanen, 1979) to describe what people do and why (Van Maanen \& de Rond, 2017). In this study, the researcher was immersed in the everyday life of the CCU and contributed as an "active member" (Adler \& Adler, 1987, 1994) of the unit. He was acknowledged as a researcher (with his own research agenda) and, at the same time, given his lack of medical skills, he helped the team to take care of patients in a basic way (e.g. carrying patients on stretchers, helping with administrative tasks, fixing computer issues, etc.). As a researcher, he collaborated scientifically with the practitioners of the CCU to better understand the unit's operations and improve patient safety. For instance, this collaboration led to the presentation of a co-authored paper highlighting the contribution HRO principles can make to improving patient safety at the French Society of Anesthesia \& Intensive Care Medicine Conference in 2016.

This ethnographic approach is based on rigorous observation of a small group of people with whom the researcher had personal interactions (Cunliffe, 2010). The study used a systematic observation method, which combined four different observation strategies around spatial and temporal variables:

- Fixed observation position and continuous observation over a long period of time: observation of the daily activity and practices.

- Fixed observation position and focused observation over a short period of time: accuracy of the data of the sequence being observed.

- Mobile observation position over a defined period of time: continuous monitoring of one individual over the duration of his shift to understand the subjective point of view of the observed actor and the tasks he performs.

- Mobile observation position on the duration of the event: monitoring of a problematic situation occurring in the organization and its management by the actors.

The study follows two strategies for validating the data analysis. The first is data triangulation (Eisenhardt, 1989; Yin, 2011), which involves having several sources for the empirical material. While observation notes constitute the majority of the empirical data, other types of data, particularly interviews, are used. Semi-structured interviews were conducted during the second half of the fieldwork (from April to December 2014) to obtain sufficient knowledge of 
the activity and shared experiences of the staff (Becker \& Geer, 1957). After the fieldwork stage, the results were presented to the members of the CCU to confirm the researcher's interpretation. In relation to the abductive analysis of producing explanations based on surprising empirical evidence, data triangulation reinforces the links between the new explanation and the surprising facts (Yin, 2011).The second validation strategy is based on the use of an analytical framework to support the interpretation. By using a template, it is possible to rearrange the empirical material and to surprise the researcher in order to bring out original ideas and facilitate the comparison work (Dumez, 2016). There is therefore a balance in the template between data formatting and the freedom to generate new ideas (Van Maanen \& de Rond, 2017). The practical implementation of this idea led to the empirical material being tackled through the dimensions of place, time and action, using the concept of "management situations" (Girin, 2011). Each critical care situation observed was analyzed through seven dimensions: participants, space, time, material resources, actions, outcome of actions and accountability. An organizational level of analysis was added to the framework to compare the situations encountered and the activity of the CCU at that time.

\section{Results}

Doctors in the CCU are specialists in intensive care anesthesiology - one of the first medical specialties to assess patient safety issues and their relation to error. Situated at the crossroads of unexpected situations and life-threatening emergencies, anesthesia critical care involves taking a holistic view of patient care so that the patient is not seen just as an extension of technical or technological procedures. This holistic view is also reflected in the willingness of the medical team to take a comprehensive overview of the situation and not to summarize it using a set of indicators that simplify the situation. In addition to its medical function, this CCU has a specific structure in the hospital, which is linked to its mission and history. While it has an intensive care unit, an emergency unit and a post-operation recovery unit, it is difficult to position this CCU as a standard care unit situated between the rigor of the "intensive care world" and the unexpected of the "emergency world". The CCU's activity takes place inside a dedicated space with its own medical team - a specific group of individuals working together to accomplish their mission to take care of the sickest patients in the Emergency Center, whatever the conditions.

The importance of the shared mission is a hallmark of the medical unit. Everyone plays a role in the achievement of this mission and the importance of achieving it structures behaviors. What is this mission? The interviews conducted with all the members of the organization confirmed the central role of accomplishing the mission of "shock management", 2 i.e. stabilizing patients to enable them to be treated:

"[Managing the shock] is acting on the symptoms due to the shock and not the cause. Well, you can also treat the cause but it is not the management of the shock per se. For example, for a trauma the bleeding is the cause of the shock. However, it is not the shock management that will treat the bleeding, you will treat it in the operating room. Our

\footnotetext{
${ }^{2}$ Shock refers to the medical term of a life-threatening medical condition. Shock can take several forms: cardiogenic (heart failure), hypovolemic/hemorrhagic, septic (sepsis), etc.
} 
mission is to keep the patient stable enough not to die before, during and after the surgery". (interview with the head of the unit)

Observation of the CCU's daily work over a period of 14 months made it possible to identify a number of WDS: those provided by the hospital organization (4.1) in terms of resources, schedule, dedicated spaces, etc., and others instituted by the medical team itself (4.2) in order to exchange information about the situations experienced.

\subsection{Formal Work Debate Spaces}

The data analysis shows that the beliefs and values shared by the members of the medical team and their commitment to improving safety in medical practices are influenced by WDS as well as by the patient. Four types of formal WDS were identified by observing and interviewing doctors and the medical team: Mortality and Morbidity meetings, expression meetings, medical meetings and working groups.

Mortality and Morbidity $(M \& M)$ meetings are the best known and the most documented WDS (with specific procedures, dedicated report files, guidelines from the national health authority). These M\&M meetings are held several months after the occurrence of an adverse event in order to enable more distant analysis. Unfortunately, due to their infrequency (because they are only held to discuss serious adverse events), this is the only type of meeting that was not directly observed. However, the researcher interviewed several doctors and collected secondary data about these meetings in order to understand their purpose. M\&M meetings are attended by the physicians who participated in the care management event covered by the meeting and a group of doctors comprising the responsible professor of medicine and physicians from other units. The meetings carry out systematic analysis of the case and the failures that occurred during its management which resulted in injury or death of the patient. This collective analysis covers the organizational, technical and human aspects related to patient management. The objective of an $\mathrm{M} \& \mathrm{M}$ meeting is to implement and monitor actions to improve patient safety. Based on a no-blame approach to errors, the documents resulting from an M\&M meeting do not contain any information that directly or indirectly identifies the patient and the medical practitioners involved.

Expression meetings represent the formalization of a desire to compare views about the problems the unit encounters. Held monthly, these meetings make it possible for staff to discuss any dysfunctions and to exchange information about developments affecting the unit. These meetings are interesting for two reasons. First, they involve all staff as all the professions, including night staff who are often absent from this type of meeting (which takes place during the day), are represented. The second reason is the honesty and freedom staff have to speak out during the discussions; according to the head of the unit, "everything is said: we argue, we congratulate each other". By involving all the staff, it is possible for everyone to make sense together and understand why changes will ensure a better quality of care. However, disagreements arise when changes do not make sense to the medical team. These meetings make it possible to find common ground with regard to certain decisions made by the manager. As some of the manager's decisions are focused on increasing the efficiency of the medical unit (working time optimization, resource allocation, size of the 
team during the night shift, etc.), the expression meetings are the place for staff to debate the consequences of these changes for patient safety, which can sometimes be underestimated by the manager. The friction that can arise between the manager and the fieldworkers is therefore only temporary and is resolved (most of the time) through these meetings.

Medical meetings involve physicians and interns and are where clinical cases are presented. The particularity of these meetings is that they are attended by the staff of the surgical intensive care unit as well as the staff of the CCU. Their purpose is to improve patient safety in the management of patients, in particular by avoiding failure related to the transfer of patients between different medical units (loss of information, discrepancies in care protocols, insufficient coordination, etc.). After one of these meetings, an intern mentioned that this kind of approach was uncommon because such meetings usually only take place within a care unit rather than at an inter-unit level. Beyond the technical aspect of care management, the objective of the meeting is to discuss the care strategy between the two units:

"Clinical cases are done once a month. We talk about pathology with a literature review. And then we discuss what we really did to manage a case of Crush Syndrome". 3 (Interview with a doctor)

The approach of these meetings is centered on teaching and learning and allows everyone (interns and doctors) from both medical units to share points of view and expertise. The issue of the boundary between the two care units and the potential weakness of interconnecting two components of the same system is therefore integrated into the improvement of patient safety (e.g. how to do handovers between these two units, creating a shared protocol to ensure patient safety on specific pathologies, etc.).

Working groups focus on a specific topic. They bring together different professions related to the remit of the group to integrate the different dimensions of the activity. These working groups make it possible to disseminate new practices related to the topics they study. For example, work on patient handovers led to the nurses and orderlies being involved in the handovers. The groups give doctors, interns, nurses and orderlies a forum for discussing the latest developments, enabling the team to discuss the case together in order to have a common vision of the situation. With synchronous transmission between all team members, the latest information on the care strategy is available to all and reduces the potential for loss of information, which can jeopardize patient safety. The working groups also provide the opportunity to work together on topics that are related to activity other than medical practice. Once again, this avoids over-compartmentalizing the activity by professional groups - doctors on one side, nurses and orderlies on the other - and helps to unify the different groups when they are facing extreme situations and to ensure the CCU's mission to deal with any lifethreatening emergencies. For example, the focus of one working group was on how to deal with a patient's family arriving at the CCU, because critical care is a traumatic event for the patient and also for the family. The group produced guidelines on how to tell a family about death or end of life, and it created internal training for staff to learn how to deal with death. It

\footnotetext{
${ }^{3}$ Crush Syndrome (or traumatic rhabdomyolysis or Bywater's syndrome) is prolonged muscle ischemia (https://www.hsdl.org/?abstract\&did=235885).
} 
also presented a study on how to support a patient's family members within a CCU at a medical conference in order to share the results with the medical community.

These formal WDS are acknowledged by the organization, which means that it allocates resources to them: meeting rooms, dedicated working time, communication of the findings of the working groups, etc. This acknowledgment is the subject of negotiation over the allocation of resources and the trade-offs generated by the WDS. Their outcomes may be directly related to the unit's activity (e.g. creation of a guide for families) or to the dissemination of the findings of a working group to the medical community (e.g. communication about patient and family satisfaction surveys and how to improve the conditions for receiving families in a $\mathrm{CCU})$. These formal types of WDS contrast with the informal WDS developed below.

\subsection{Informal Word Debate Spaces}

As they are acknowledged by the organization, formal WDS are planned and therefore easily identifiable. By studying their time scope, space and practice, it was also possible to identify which types of WDS they do not include. Within care situations, there are also more elusive and informal WDS which are mainly oral in form (discussions, dialogues, debates). These spaces therefore leave few tangible traces, making it much more difficult to study them. Four types of informal WDS were identified in this study: debriefings following adverse events, discussions following treatment of a patient, discussions about medical practice and discussions about problems encountered by caregivers in the course of their work.

Debriefings following adverse events are held to understand what happened and what might have happened. These debriefings, which last less than an hour, are held in doctors' offices, over coffee or during meals. However, they can also take place sporadically over a period of a few days to several weeks. Their duration depends on the seriousness of the situation and its impact on the patient. For example, the death in the operating room of a patient who had come for a common operation (appendectomy with no complications or particular antecedents) led to multiple debriefings over a period of a month. In most cases, these debriefings involve doctors and interns, but they can sometimes involve the nurses and orderlies who were present during the situation. More rarely, an external member of the unit may be involved (for example, the professor of anesthesia participated in discussion with the unit's doctors about the aforementioned appendectomy situation). Feedback is therefore not limited to formal elements, and informal spaces are also involved. Even if the appendectomy event had initiated an M\&M meeting - which did not occur during the fieldwork - these informal debriefings fulfill different purposes to those of $M \& M$ meetings. They emphasize teamwork where everyone plays a role in the achievement of the CCU's mission, and where everyone can make mistakes that can be collectively discussed outside more formal structures.

The discussions following treatment of a patient last for 5 to 10 minutes just after the situation has taken place. They involve the team that provided the care (doctor, intern, nurse and orderly) to discuss what has just happened. The discussions can also take place later, during the handover between shifts. One example is where an error during surgery resulted in a patient being injected with the wrong drug. This caused more anaphylactic shock and the clinical condition of the patient contra-indicated its use with a risk of hyperkalemia (excessive 
potassium in the blood which can lead to cardiac arrhythmia and potentially cardiac arrest). The error stemmed from the ampoules of the products to be injected being in two adjacent compartments and being of the same shape and color. As well as making practical recommendations about labeling and the design of the anesthesia trolleys, the senior physician valued the intern's behavior, saying: "she reacted appropriately"; "she called for help"; "she didn't deal with this situation alone"; "trust the team"; "mistakes happen to even the most experienced". These quotes illustrate the two values of competence and humility promoted by the CCU: the members of the unit are highly skilled professionals who know how to deal with life-threatening situations, but recognizing its limits also means valuing teamwork where everyone relies on each other to accomplish the CCU's mission.

The discussions about medical practices cover numerous discussions among physicians about changes in their medical practice. Discussions about improving practice are part of everyday life (especially during meals or breaks) in informal situations. Work topics come up in these discussions that might subsequently be considered in formal WDS (e.g. in working groups). They include discussions about care protocols (e.g. traffic accident criteria for admission to the $\mathrm{CCU}$ ), technical procedures (e.g. systematic use of echography for central venous lines to avoid pneumothorax) and legislative changes (e.g. on organ donation). As well as the medical practices per se, safety also involves more organizational elements such as the recruitment of new doctors, which has two specific characteristics. First, the head of the unit seeks the opinion of each of the other doctors on the future doctor. The candidate is unanimously selected. The selection of a new doctor is made by co-optation following a long process whereby interns are identified as potential candidates during their internship and are then evaluated during their chief residency. Second, the job profile reflects the need for candidates to have a high degree of expertise to deal with life-threatening situations. In addition, there is a need to balance a variety of competences within the CCU to respond to the various quantitative and qualitative situations that will arise.

The discussions about problems encountered by caregivers in the course of their work are the last and the most fleeting form of informal WDS. They take place in small groups over a meal, a coffee, or spontaneously in response to a recent event. As well as discussing ongoing issues related to usual events encountered in the CCU, most of these discussions focus on how organizational changes might impact medical practices and safety. Tracking software for a new blood product was the subject of several discussions during the fieldwork, because of its many bugs and the problems created by time delays for packed red blood cells in a medical unit where only a few minutes separate life from death. While improving the safety of blood transfusions through better traceability is positive in theory, it has an impact on services where the time frame for critical care is counted in minutes. Such discussions precede the formalization and discussion that follow in formal WDS (such as expression meetings or working groups) if required by the seriousness of the problem. They are not just "small talk" about what staff do not like in their work; they are the first step in linking the CCU's daily activity with organizational change. 
These informal WDS are invisible to the organization (i.e. the hospital) but they play a key role in building safety. Their invisible nature is corroborated by the absence of allocated resources (procedures, time, rooms, etc.). These spaces are fragmented and scattered throughout the activity and the everyday life of the CCU (during meals, coffee breaks, etc.). As they take place during what can be described as idle time, they may be belittled by the organization. However, they are essential for two main reasons. The first is their temporality, which ensures rapid feedback about the situations encountered. Informal WDS are thus free of any organizational inertia related to planning and formal stakeholder coordination. They enable quick and practical feedback for the people involved in the situation, whether this is just the team that is involved or the entire staff of the unit. The second reason why they are essential is because of what is said in these informal spaces. Although based on trust and respect for each other's expertise, the discussions are nevertheless direct and intense. In addition, these informal spaces are not scrutinized by the organization, especially when discussing the still-taboo question of error. In these informal spaces, anonymity provides protection from the organization and enables staff to have a relationship with error that is free of sanction and not subject to peer judgment.

WDS are structured within the CCU or, in one case, between the CCU and another medical unit and, over time, they carry the collective experience of the unit's activity. This study shows that culture (and how to change it) depends on organizational spaces as well as the situations encountered. Over time, WDS support the reinforcement or readjustment of the culture. As well as carrying a set of stories/principles which shape the identity and the culture of the medical team studied, these organizational spaces enable organizational learning and changes to practice, and they improve patient safety. Informal WDS are therefore not transient or incomplete types of spaces. However, the very local nature of informal spaces raises the question of whether they have a compartmentalizing effect which may result in them reinventing or discovering practices that already exist in other units. Information exchanged at the rapid, local, informal level must therefore be balanced with information at the slow, formal, organizational (and more institutionalized) level. One type of WDS is no better than the other; they are complementary and operate at different temporalities.

\section{Discussion}

This study addresses the lack of information on how WDS work in practice (Rocha et al., 2019). Although Detchessahar (2013) refers to WDS that can be accommodated informally in the activity, there is little in the literature to explain how this works and, in particular, how the different forms of WDS in an organization are articulated. In this case study, WDS take forms depending on the situations experienced and their intensity. Studying these WDS demonstrates the fleeting nature of some and contributes to a better understanding of their role in bringing together collective experience over time. Whether WDS are formal or more informal, they enable the medical unit to change to ensure patient safety. The findings also highlight how interactions within the WDS lead, over time, to the construction of a culture focused on the importance of the mission and the priority of managing the unplanned flow of patients whose condition constitutes a life-threatening emergency. This importance of mission - widely documented in the literature (Boin \& Schulman, 2008; La Porte \& Consolini, 1991; 
Roberts, 1990; Rochlin et al., 1987) - reveals that beyond the discussion of practices within these WDS, it is the set of values and behaviors that are disseminated there (especially to newcomers) that are at the core of the unit's identity.

These inter-related WDS enable a more refined approach to understanding the relationship between structure and culture. However, this approach raises a question about the level of organizational acknowledgment needed to ensure the existence of these spaces. Acknowledgment of these spaces by the organization results in resources being provided for them, but, if patient safety is to be improved, this acknowledgment cannot be limited to institutionalized practices. Of the WDS discussed in this paper, only the M\&M meetings are institutionalized and widely used in the healthcare sector. However, medical meetings or expression meetings occur in other units (particularly in intensive care units), highlighting the central role of the mission in the construction of these WDS. The culture of the CCU (which is linked to its activity) is not just a descriptive label but is based on organizational structures. The institutionalization of these spaces must be linked to the activity of the care unit. The Adverse Event Reporting System implemented in the hospital in this study highlights the institutionalization of a practice that does not comply with the activity. The practitioners themselves point out its limits: adverse events are under-reported due to a lack of concrete and direct feedback and, as there is a focus on serious adverse events rather than on adverse events in general, most "risk-carrying events" are ignored (Brami \& Amalberti, 2010).

The study of WDS in a CCU also provides a more refined understanding of the construction of reliability and resilience. First, the results highlight the importance of "interstitial activities" (Eydieux et al., 2016). Following the interactionist approach to reliability and resilience, which focuses on dialogue, clarification or negotiation (e.g. Kellogg et al., 2006; Tillement et al., 2009), the notion of interstitial activity emphasizes the idea that reliability is not just about activities that make up an organization's "core business" (in this case, critical care management) but refers to activities that also ensure reliability and are often ignored in the analysis (Eydieux et al., 2016). Interstitial spaces are therefore vehicles for socialization and discussion processes regarding the critical situation encountered. Informal WDS can be related to interstitial spaces contrasting with the more formal or institutionalized forms. The oral nature of these interstitial activities - discussions, dialogues, debates - leave little material evidence, making them even more difficult to study. These activities are both invisible - from an organizational perspective, with no dedicated procedures, times or places - and crucial to ensuring resilience and reliability.

Ensuring reliability and resilience requires organizational spaces away from the action to prevent organizational reliability and resilience being considered as a collection of situations. Following the insights of Bechky and Okhuysen (2011), WDS shed light on the long-term construction of reliability and resilience by providing organizational feedback on situations encountered. The enactment of the (past) situation experienced within the WDS (present) will bring the past situation into the (future) organization. WDS enable different perspectives of the situation to be brought together: the perspectives of the team who dealt with the situation as well as the other members of the unit's team. It is within the WDS, that the sense of the 
situation is negotiated (Schulman, 1993). These spaces therefore have a mediating role, which adjusts processes by reinforcing or modifying them over time according to the situations encountered: consolidation of the collective identity, recruitment of a new member, improvement of medical practices, etc.

Finally, this study provides insight into the relationship between structure, culture and activity. In line with Hopkins (2019), the study contributes to the idea that safety cannot be improved by an individual approach (like "hearts and minds" educational programs) alone. Organizational structure must be part of the journey too. However, if structure shapes culture, the structural elements may not be visible to the hospital administration because of the tension between institutionalization and flexibility. It is not a matter here of opposing "emerging" and "managerialist" cultures (Hopkins, 2018) but rather of integrating the dynamics between the localism and institutionalization of WDS. Similarly, this should not ignore the issue of resource allocation. The level at which the organization recognizes and is interested in these invisible structural elements will affect the associated resources required. The resources allocated to these structural spaces can be the same as those that are made available to formal WDS. However, they can also be allocated through a symbolic and unprescribed laissez-faire approach.

Studying a CCU responds to the call by Grote (2012) for a more detailed understanding within different industries of the "making of safety" according to the tasks and the mission completed. This case study of a CCU offers a different angle, away from the industries that are traditionally studied, to understand the complex relationship between safety, structure and culture. For instance, the tension around the priority for safety between organizational structure (centralized) and professional identity (decentralized) highlights the need for a dynamic approach that focuses on organizing - the way organization organizes itself (Weick, 1979) - rather than a static representation of culture and structure. This decentralized approach could borrow from the "Anarchist School" (Dekker, 2017; Hopkins, 2019). Does it refute Hopkins' idea that "structure creates culture"? On the contrary, this study corroborates this idea and the distinction between the context of major hazards, where the structuralist approach matters, and other contexts, where an anarchist approach may be relevant: "safety anarchism is utterly inapplicable for major hazard risk. [...] Those who seek to generalize it to this context should be very careful indeed" (Hopkins, 2019, p. 46).

Three additional comments can be made to this discussion about structure and culture. First, in line with Hopkins (2019), it is important to be careful about generalizing the "structure creates culture" idea as relating to all contexts. The distinctive criterion of major hazard risk is not so easy to manipulate. One adverse event in medicine has less quantitative impact than a nuclear accident. However, despite the controversy that surrounds the issue of estimating the number of deaths due to medical error (Shojania \& Dixon-Woods, 2017), 25,000 deaths per year could be averted in the US by eliminating medical error. Second, this study raises questions about how "safety procedures" are created and how structure adapts as a result of unexpected situations. The time when action is being taken to deal with these situations is not the time when procedures should be created. What should be done when dealing with 
unexpected or unimagined events (Weick \& Sutcliffe, 2007)? As Todd R. La Porte stated, "the problem is not to prepare to avoid surprises, but to prepare to be very surprised" (cited by Lagadec, 2015, p. 12). The dialogic approach between activity and structure (through WDS) connects the different temporalities of organizing for safety. Last, Hopkins' view that "structure creates culture" should be understood as being in opposition to the individual approach to safety. This provocative sentence is intended to highlight the role (and accountability) of organizational structure (and its leaders) in the "making of safety". Thus, it rightly highlights the issue of the power structure and glass ceiling that can sometimes be observed in relation to these safety issues. This glass ceiling can only be broken from the top, through the power of the leaders.

To conclude, two directions for future research are suggested. The first relates to studying WDS at the hospital level of analysis. An interesting avenue for further research could be to investigate how the outcomes from the WDS spray across the organization and among other medical units. The second avenue for future research would be to investigate the distinction between sectors with major hazards (and the structuralist approach to safety) and sectors without major hazards (and the anarchist approach to safety). A longitudinal study of a CCU could help to compare this sector with more traditional ones (e.g. civil aviation, nuclear, oil and gas industry) in order to create an integrative framework.

\section{References}

Adler, P. A., \& Adler, P. (1987). The past and the future of ethnography. Journal of Contemporary Ethnography, 16(1), 4-24.

Adler, P. A., \& Adler, P. (1994). Observational Techniques. In N. K. Denzin, and Y. S. Lincoln (Eds.), Handbook of Qualitative Research (Thousand Oaks, CA: Sage Publications, pp. 377-392).

Amalberti, R., \& Wioland, L. (1997). Human error in aviation. In H. M. Soekkha (Ed.), Aviation safety: Human factors, system engineering, flight operations, economics, strategies, management (VSP International Science Publishers, pp. 91-108).

Bechky, B. A., \& Okhuysen, G. A. (2011). Expecting the unexpected? How SWAT officers and film crews handle surprises. Academy of Management Journal, 54(2), 239-261.

Becker, H. S., \& Geer, B. (1957). Participant observation and interviewing: A comparison. Human Organization, 16(3), 28-32.

Bierly, P. E., \& Spender, J.-C. (1995). Culture and high reliability organizations: The case of the nuclear submarine. Journal of Management, 21(4), 639-656.

Boin, A., \& Schulman, P. (2008). Assessing NASA's Safety Culture: The Limits and Possibilities of High-Reliability Theory. Public Administration Review, 68(6), 10501062. 
Bourrier, M. (2011). The legacy of the High Reliability Organization project. Journal of Contingencies and Crisis Management, 19(1), 9-13.

Brami, J., \& Amalberti, R. (2010). La sécurité du patient en médecine générale. Springer.

Cole, K. S., Stevens-Adams, S. M., \& Wenner, C. A. (2013). A Literature Review of Safety Culture. Sandia National Laboratories.

Cunliffe, A. L. (2010). Retelling tales of the field: In search of organizational ethnography 20 years on. Organizational Research Methods, 13(2), 224-239.

Dekker, S. (2017). The safety anarchist: Relying on human expertise and innovation, reducing bureaucracy and compliance. Routledge.

Denison, D. R. (1996). What is the Difference between Organizational Culture and Organizational Climate? A Native's Point of View on a Decade of Paradigm Wars. The Academy of Management Review, 21(3), 619-654.

Detchessahar, M. (2013). Faire face aux risques psycho-sociaux: Quelques éléments d'un management par la discussion. Négociations, 19(1), 57-80.

Detchessahar, M., Gentil, S., Grevin, A., \& Journé, B. (2017). Between noise and silence, engineering a dialog about work: Maintenance projects in a high-risk industry. Gérer et Comprendre, Annales Des Mines, 130(4), 33-45.

Detchessahar, M., \& Journé, B. (2018). Managing Strategic Discussions in Organizations: A Habermasian Perspective.M@n@gement,21(2),773-802.

Dumez, H. (2016). Méthodologie de la recherche qualitative. Vuibert.

Eisenhardt, K. M. (1989). Building theories from case study research. Academy of Management Review, 14(4), 532-550.

Eydieux, J., Journé, B., \& Tillement, S. (2016). Organizational reliability seen through interstitial activities. Annales des Mines - Gérer et comprendre, 126(4), 15-27. Cairn.info.

Gaba, D. M., Singer, S. J., Sinaiko, A. D., Bowen, J. D., \& Ciavarelli, A. P. (2003). Differences in safety climate between hospital personnel and naval aviators. Human Factors, 45(2), 173-185.

Gilbert, C., Journé, B., Laroche, H., \& Bieder, C. (Eds.). (2018). Safety Cultures, Safety Models: Taking Stock and Moving Forward. Springer International Publishing.

Girin, J. (2011). Empirical analysis of management situations: Elements of theory and method. European Management Review, 8(4), 197-212.

Grote, G. (2012). Safety management in different high-risk domains-all the same? Safety Science, 50(10), 1983-1992. 
Hällgren, M., Rouleau, L., \& de Rond, M. (2018). A Matter of Life or Death: How Extreme Context Research Matters for Management and Organization Studies. Academy of Management Annals, 12(1), 111-153.

Hopkins, A. (2006). Studying organisational cultures and their effects on safety. Safety Science, 44(10), 875-889.

Hopkins, A. (2018). The Use and Abuse of "Culture." In C. Gilbert, B. Journé, H. Laroche, \& C. Bieder (Eds.), Safety Cultures, Safety Models: Taking Stock and Moving Forward (pp. 35-46).

Hopkins, A. (2019). Organising for Safety: How Structure Creates Culture. CCH Australia Limited.

Hudson, P. (2007). Implementing a safety culture in a major multi-national. Safety Science, 45(6), 697-722.

Kellogg, K. C., Orlikowski, W. J., \& Yates, J. (2006). Life in the trading zone: Structuring coordination across boundaries in postbureaucratic organizations. Organization Science, 17(1), 22-44.

Kohn, L. T., Corrigan, J., \& Donaldson, M. S. (2000). To error is human: Building a safer health system. National Academy Press.

La Porte, T. R. (1996). High Reliability Organizations: Unlikely demanding and at risk. Journal of Contingencies and Crisis Management, 4(2), 60-71.

La Porte, T. R., \& Consolini, P. (1991). Working in practice but not in theory: Theoretical challenges of 'High Reliability Organizations'. Journal of Public Administration Research and Theory, 1(1), 19-47.

Lagadec, P. (2015). Le continent des imprévus: Journal de bord des temps chaotiques. Manitoba Les Belles Lettres.

Madsen, P., Desai, V., Roberts, K. H., \& Wong, D. (2006). Mitigating hazards through continuing design: The birth and evolution of a pediatric intensive care unit. Organization Science, 17(2), 239-248.

Pidgeon, N. (1997). The Limits to safety? Culture, politics, learning and man-made disasters. Journal of Contingencies and Crisis Management, 5(1), 1-14.

Reason, J. T. (1997). Managing the risks of organizational accidents. Ashgate Publishing, Ltd.

Reason, J. T. (2005). Safety in the operating theatre-Part 2: Human error and organisational failure. Quality and Safety in Health Care, 14(1), 56-60.

Roberts, K. H. (1990). Some characteristics of one type of high reliability organization. Organization Science, 1(2), 160-176. 
Roberts, K. H., Madsen, P., Desai, V., \& Van Stralen, D. (2005). A case of the birth and death of a high reliability healthcare organisation. Quality and Safety in Health Care, 14(3), 216-220.

Roberts, K. H., Rousseau, D. M., \& La Porte, T. R. (1994). The Culture of High-Reliability: Quantitative and Qualitative Assessment aboard Nuclear-Powered Aircraft Carriers. The Journal of High Technology Management Research, 5(1), 141-161.

Rocha, R., Mollo, V., \& Daniellou, F. (2015). Work debate spaces: A tool for developing a participatory safety management. Applied Ergonomics, 46, 107-114.

Rocha, R., Mollo, V., \& Daniellou, F. (2019). Contributions and conditions of structured debates on work on safety construction. Safety Science, 113, 192-199.

Rochlin, G. I., La Porte, T. R., \& Roberts, K. H. (1987). The self-designing high-reliability organization: Aircraft carrier flight operations at sea. Naval War College Review, 40(4), 76-90.

Schein, E. H. (1990). Organizational culture. American Psychologist, 45(2), 109-119.

Schulman, P. R. (1993). The negotiated order of organizational reliability. Administration \& Society, 25(3), 353-372.

Shojania, K. G., \& Dixon-Woods, M. (2017). Estimating deaths due to medical error: The ongoing controversy and why it matters. BMJ Quality \& Safety, 26(5), 423-428.

Tillement, S., Cholez, C., \& Reverdy, T. (2009). Assessing organizational resilience: An interactionist approach. $M @ n @ g e m e n t, 12(4), 230-264$.

Van Maanen, J. (1979). The fact of fiction in organizational ethnography. Administrative Science Quarterly, 24(4), 539-550.

Van Maanen, J., \& de Rond, M. (2017). The making of a classic ethnography: Notes on Alice Goffman's On the Run. Academy of Management Review, 42(2), 396-406.

Van Maanen, J., Sørensen, J. B., \& Mitchell, T. R. (2007). The interplay between theory and method. Academy of Management Review, 32(4), 1145-1154.

Weick, K. E. (1979). The Social Psychology of Organizing (Second Edition). Longman Higher Education.

Weick, K. E. (1987). Organizational culture as a source of high reliability. California Management Review, 29(2), 112-127.

Weick, K. E., \& Roberts, K. H. (1993). Collective mind in organizations: Heedful interrelating on flight decks. Administrative Science Quarterly, 38(3), 357-381.

Weick, K. E., \& Sutcliffe, K. M. (2007). Managing the unexpected: Resilient performance in an Age of Uncertainty. Edition Jossey-Bass Inc.

Yin, R. K. (2011). Qualitative research-From start to Finish. The Guilford Press. 